\title{
The Role of Energy in the Industrial Revolution and Modern Economic Growth
}

\author{
David I. Stern* and Astrid Kander**
}

The expansion in the supply of energy services over the last couple of centuries has reduced the apparent importance of energy in economic growth despite energy being an essential production input. We demonstrate this by developing a simple extension of the Solow growth model, which we use to investigate 200 years of Swedish data. We find that the elasticity of substitution between a capital-labor aggregate and energy is less than unity, which implies that when energy services are scarce they strongly constrain output growth resulting in a low income steady-state. When energy services are abundant the economy exhibits the behavior of the "modern growth regime" with the Solow model as a limiting case. The expansion of energy services is found to be a major factor in explaining economic growth in Sweden, especially before the second half of the 20th century. After 1950, labor-augmenting technological change becomes the dominant factor driving growth though energy still plays a role.

Keywords: Unified growth theory, Energy, Industrial Revolution, Economic growth

http://dx.doi.org/10.5547/01956574.33.3.5

\section{INTRODUCTION}

How can energy play a major role in the long-run growth of the economy and be crucial in explaining the Industrial Revolution yet occupy a small share of the costs of production in today's advanced economies? We develop a simple

* Corresponding author. Crawford School of Economics and Government, Australian National University, Canberra, ACT 0200, Australia. E-mail: david.stern@anu.edu.au.

** Department of Economic History, Lund University, Lund, Sweden. E-mail: Astrid.Kander@ ekh.lu.se.

We thank Stephan Bruns, Paul Burke, Creina Day, Helena Johansson, Jack Pezzey, Peter Warr, Fredrik Wilhelmsson, and four anonymous referees for providing useful comments, and Lennart Schön for providing unpublished data.

The Energy Journal, Vol. 33, No. 3. Copyright (C) 2012 by the IAEE. All rights reserved. 
Figure 1: Sweden 1800-2000, Value of Energy/GDP

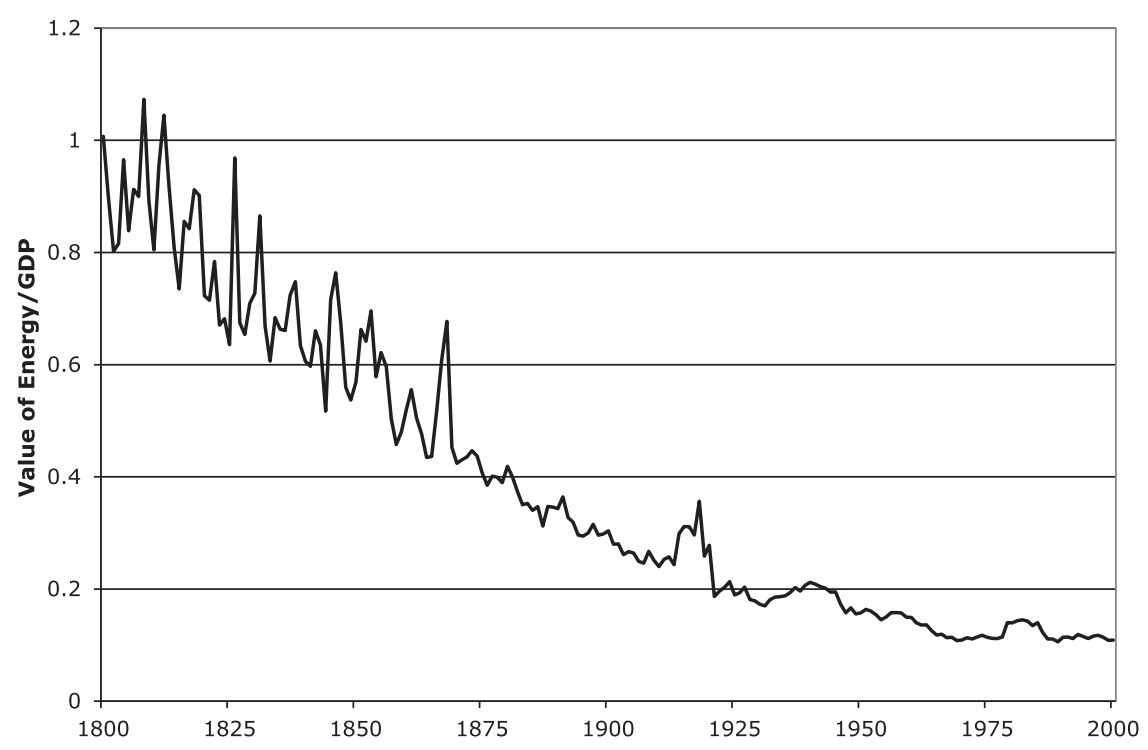

model that extends Solow's (1956) neoclassical growth model to include energy and estimate its parameters using two centuries of Swedish data. The model shows that the expansion of energy services was the most important factor explaining growth until the second half of the 20th century when labor-augmenting technical change becomes paramount. Additionally, the model can explain the historical decline in the energy cost share seen in the Swedish data (Figure 1), which Smulders and de Nooij (2003) describe as a stylized fact of economic development. ${ }^{1}$

Many energy and ecological economists (e.g. Cleveland et al., 1984; Ayres and Warr, 2005, 2009, Hall et al., 2003), geographers (e.g. Smil, 1994), as well as some (e.g. Cipolla, 1962; Wilkinson, 1973; Wrigley, 1988; Allen, 2009) but not all (Landes, 1969; Clark, 2007) economic historians believe that energyrelated innovations and the growth in the quantity and quality of energy play a crucial role in economic growth, as well as being important in explaining the Industrial Revolution. Time-series analysis (Stern, 1993, 2000) shows that energy is needed in addition to capital and labor to explain the growth of GDP. But mainstream economics research has tended to downplay the importance of energy in economic growth. The principal models used to explain the growth process (e.g. Aghion and Howitt, 2009) do not include energy as a factor of production.

1. This and other stylized facts were based on data for the USA (Jones, 2002). Evidence for other countries is limited but shows a declining cost share for the United Kingdom in the 19th century, even though energy intensity rose. This was because the real price of coal fell drastically in the UK compared to the GDP deflator over this period (Kander et al., forthcoming). 
As our model will show, this omission is probably because energy has been very abundant in recent decades in developed economies and its cost share low, so that the constraints imposed by energy availability on economic growth are weaker than they were in the past. On the other hand, there is a large literature examining whether sustainable per capita consumption or utility is feasible in the face of the non-renewable nature of some resources starting with Solow (1974), Dasgupta and Heal (1974), and Stiglitz (1974), through Aghion and Howitt (1998), to recent contributions such as Di Maria and Valente (2008). These models do not, however, usually specify whether the resources in question are energy or non-energy resources. Neither do they attempt to model a realistic historical economic development path. An exception is Tahvonen and Salo (2001), who model past and possible future energy transitions between renewable and non-renewable energy explicitly. In their model, the dominant energy vector switches from renewable to non-renewable energy and back again over the course of economic development. The drivers of these shifts are the different price paths of the two sources of energy over the course of economic development. Though this latter paper is much more historically realistic than most work in resource economics, it does not directly address the importance (or not) of energy in economic growth and its role in the Industrial Revolution.

There are two principal mainstream economic models of the transition from the pre-industrial economy to the modern growth regime. The endogenous technical change approach represented by Galor and Weil (2000) and Lucas (2002) emphasizes the role of human capital and fertility decisions in the transition. The rate of technological change in Galor and Weil's model is a function of the size of the population and the level of education. Initially, there is a steadystate equilibrium that has a low rate of technological change and a low level of education. As population grows, a second fast technological change and high education equilibrium emerges, which eventually is the only equilibrium (Galor, 2005). Energy and resources play no explicit role in this approach. The implicit assumption is that energy was never a significant limiting factor.

The second approach, represented by Hansen and Prescott (2002), assumes that two technologies are available - the Malthus technology, which depends on a land input and has decreasing returns to combined labor and capital and the modern Solow technology that has constant returns to capital and labor combined, and does not face any natural resource constraints. Initially, the use of the Solow technology is unprofitable and the economy experiences pre-industrial stagnation. The transition to the modern growth regime starts when technological change first makes the operation of the modern technology profitable and the economy becomes a dual economy with modern and traditional sectors. Over time, the modern sector grows and the traditional sector declines as capital flows from the traditional to modern sector. Hansen and Prescott (2002) note that the Solow technology probably uses fossil fuels in place of land, but they do not model energy explicitly. 
Economic history provides some qualitative models of the Industrial Revolution, where the breaking of the constraints of the organic economy plays a fundamental role. Wrigley $(1988,2010)$ stresses that the shift from an economy that relied on land resources to one based on fossil fuels is the essence of the Industrial Revolution and could explain the differential development of the Dutch and British economies. Both countries had the necessary institutions for the Industrial Revolution to occur but capital accumulation in the Netherlands faced a renewable energy resource constraint, while in Britain domestic coal mines in combination with steam engines, at first to pump water out of the mines and later for many other uses, provided a way out from the constraint. Early in the Industrial Revolution, the transport of coal had to be carried out using traditional energy carriers, for instance by horse carriages, and was very costly, but the adoption of coal-using steam engines for transport, reduced the costs of trade and the Industrial Revolution spread to other regions and countries. This explanation emphasizes the low substitutability between the essential inputs of capital and energy, with newly available punctiform energy sources (coal) relaxing the constraint on capital accumulation. With only restricted areal-bound resources, capital accumulation faced rapidly diminishing returns.

Pomeranz (2001) makes a similar argument, but addresses the issue of the large historical divergence in economic growth rates between England and the Western World on the one hand and China and the rest of Asia on the other. He suggests that shallow coal-mines, close to urban centers together with the exploitation of land resources overseas were very important in the rise of England. "Ghost land", used for the production of cotton for the British textile industry provided England with natural resources, and eased the constraints of the fixed supply of land. In this way, England could break the constraints of the organic economy (based on land production) and enter into modern economic growth.

Allen (2009) places energy innovation centre-stage in his explanation of why the industrial revolution occurred in Britain. Like Wrigley and Pomeranz, he compares Britain to other advanced European economies of the time (the Netherlands and Belgium) and the advanced economy in the East: China. England stands out as an exception in two ways: coal was relatively cheap there and labor costs were higher than elsewhere. Therefore, it was profitable to substitute coalfuelled machines for labor in Britain, even when these machines were inefficient and consumed large amounts of coal. In no other place on Earth did this make sense. Many technological innovations were required in order to use coal effectively in new applications ranging from domestic heating and cooking to iron smelting. These induced innovations sparked the Industrial Revolution. Continued innovation that improved energy efficiency and reductions in the cost of transporting coal eventually made coal-using technologies profitable in other countries too. On the other hand, Madsen et al. (2010) find that, controlling for a number of innovation related variables, changes in coal production did not have a significant effect on labor productivity growth in Britain between 1700 and 1915. But as innovation was required to expand the use of coal this result could 
make sense even if the expansion of coal was essential for growth to proceed. Additionally, as Madsen et al.'s (2010) regression is in first differences, they can only measure the direct short-run impact effect of changes in energy use.

Our aim is to examine a simple model of the breaking of the constraints imposed by dependence on the organic economy and the shift towards the modern growth regime. For the sake of simplicity, and to allow comparison with the results of other models, we base our model on Solow's (1956) neoclassical growth model, which is still considered a benchmark in growth modeling (Jones and Manuelli, 2005; Brock and Taylor, 2010). We add an energy input that may have an elasticity of substitution of less than unity with capital and labor, while we set the elasticity of substitution between capital and labor at unity. Additionally, we allow for the possibility of biased technical change. Rather than treating technology as a single index of total factor productivity, there are two indices-one augments labor (and implicitly capital) and the other augments energy. ${ }^{2}$ Energyaugmenting technical change represents all methods of obtaining more economic output from a given energy input without substituting capital and labor for energy or augmenting the other inputs through technological change. This includes both greater energy efficiency in producing existing products and the development of new products such as steam engines and computers that use energy in new, more productive ways. The Industrial Revolution involved both innovations that effectively augmented the supply of energy, for instance the smelting of iron ore with coke instead of charcoal, increases in the energy supply (coal from deep mines), and improvements in the quality of the energy sources used. We can think of effective energy services as the product of the joules of energy used, the quality of that energy, ${ }^{3}$ and the level of energy-augmenting technology. Because the purpose of the empirical section of the paper is to measure the relative roles of technological change and the changes in energy quantity and quality on growth, we assume that technological change is exogenous.

2. A similar approach is taken in a number of recent resource economics papers such as Di Maria and Valente (2008) and Fröling (2011). Factor-augmenting technological change increases the effective amount of an input. In other words, a 1\% advance in labor- (energy-) augmenting technological change will have exactly the same effect on output as a $1 \%$ increase in the quantity of labor (energy). Effective labor (energy) is the product of the quantity of labor (energy) and the labor (energy) augmenting technology index. We also use the term "energy services" to refer to effective energy.

3. In this paper, the quality of total energy (rather than of individual energy vectors) refers to the ratio of a price weighted volume index of energy use to the simple sum of total joules. We assume that more productive or "higher quality" energy carriers have higher prices and so this ratio reflects the increase in the productivity of the energy input due to the shift over time to higher quality energy carriers such as primary electricity and natural gas from lower quality fuels such as coal and biomass. In the empirical work we account for the effect of shifts in the mix of energy carriers on energy quality by employing a Divisia index of energy use rather than the simple sum of heat units. Though such indexation methods account for the shift from lower quality (less productive) to higher quality (more productive) fuels they do not take account of the increased productivity of individual fuels (Stern, 2010a). The latter are ascribed to energy-augmenting technological change. Also we note that the term "energy" used throughout the paper actually refers to available energy or exergy. 
Why do we use a general constant elasticity of substitution (CES) production function rather than the more commonly used Cobb-Douglas function, which imposes an elasticity of substitution of one? First, it enables a simple model with only one sector rather than the two sectors in Hansen and Prescott, while allowing a change in the degree to which energy constrains growth within that sector over time. Second, thermodynamic considerations suggest that production of a given level of output has minimum energy requirements (Stern, 1997). When the elasticity of substitution is less than unity there is a finite minimum energy requirement for any level of output irrespective of the level of the other inputs. Third, empirical evidence suggests that the elasticity of substitution between capital and energy is less than one (Koetse et al., 2008). Fourth, the cost share of energy in Sweden, where we have data from 1800 till the present, fell dramatically over time from an energy cost ratio of $90 \%$ of GDP or more in 1800 to close to $10 \%$ of GDP today (Figure 1). This is not possible for a single sector economy with an elasticity of substitution of unity (Cobb-Douglas technology), which implies that cost shares are constant. Fifth, we cannot distinguish between laboraugmenting innovations and energy-augmenting innovations in a Cobb-Douglas technology, which implies that technological change is factor neutral. For a nonCobb-Douglas constant elasticity of substitution (CES) technology, labor-augmenting technical change does not augment the energy supply.

An alternative approach is to think of energy services as being produced by capital and energy, which then combine with labor to produce final output. We do not use that approach because it assumes that the elasticities of substitution between energy and labor and between capital and labor are equal. In a preindustrial society a major use of energy was as food for workers such that there may also be limited substitutability between labor and energy. Furthermore, our model nests the Solow (1956) growth model as a special case, which is useful for expository purposes, while the alternative model does not.

Fröling's (2011) unified growth model is the closest previous research to this paper. Her model is an example of Galor and Weil's (2000) approach as population growth drives the rate of endogenous technical change and there is no real energy constraint on production. In her model, energy services are a high (elasticity of substitution greater than one) CES aggregate of coal and biomass, which are each produced using labor alone. So the size of the labor force rather than land or other resource constraints also drives energy availability. Innovative activity, which also only uses labor, leads to the accumulation of two stocks of knowledge one of which enhances TFP in the production of final output while the other enhances the productivity of coal in producing energy services. Biomass is only distinguished from coal in that knowledge cannot enhance its productivity. Thus the shares of biomass and coal change over time. Labor is used in five separate activities and research expenditures in each sector are assumed to be a constant share of final output much as saving is a constant share of output in the Solow model. Population evolves according to Jones' (2001) demographic model. As final output is produced by a Cobb-Douglas function of labor, aggregate en- 
ergy services, and a fixed quantity of land, the model cannot reproduce the decline in the total energy cost share, which we see in our data, whereas our model can. Additionally, there is no capital stock in Fröling's model while our model can exploit the available capital data.

The next section of the paper outlines our theoretical model and its properties. This analysis shows how energy availability and the level of energyaugmenting technology can constrain the rate of economic growth. This is followed by the discussion of the Swedish data and the econometric methods and results. We use the estimated parameters in a historical simulation as well as several counterfactual simulations in each one of which we hold one of the exogenous variables constant in order to determine the importance of each variable on economic growth in Sweden. The paper concludes with a discussion section.

\section{THEORETICAL MODEL}

Our model aims at explaining a major shift in economic history. This can be thought of as a shift in the economy's long-run equilibrium or steady-state from one with low output to one with high output due to an increase in the availability of effective energy services. Similarly, continued expansion of effective energy services allowed a higher rate of economic growth than in the preindustrial period because expanding energy services continually moved the steady-state to higher levels of output. This section of the paper examines the properties of this model focusing on the steady-state both because it is the longrun equilibrium towards which the economy is tending and because analysis of the steady-state is fairly straightforward compared to non-equilibrium states.

\section{The Model}

Omitting time indices for simplicity, the model consists of two equations:

$$
\begin{aligned}
& Y=\left(\gamma_{V}^{1 / \sigma}\left(A_{L}^{\beta} L^{\beta} K^{1-\beta}\right)^{\phi}+\gamma_{E}^{1 / \sigma}\left(A_{E} E\right)^{\phi}\right)^{\frac{1}{\phi}} \\
& \Delta K=s Y-\delta K
\end{aligned}
$$

Equation (1) is a nested CES production function that embeds a Cobb-Douglas function of capital $(K)$ and labor $(L)$ in a CES function of the capital-labor aggregate and energy $(E)$ that determines gross output $Y \cdot^{4} \phi=\frac{\sigma-1}{\sigma}$, where $\sigma$ is the

4. The Cobb-Douglas function is a CES function with an elasticity of substitution of unity. In contrast to GDP, which is a measure of value added, gross output does not net out the value of intermediate inputs. 


\section{2 / The Energy Journal}

elasticity of substitution between energy and the capital-labor aggregate. The share parameters $\gamma_{E}$ and $\gamma_{V}$ sum to unity. ${ }^{5} A_{L}$ and $A_{E}$ are the augmentation indices of labor and energy. Effective energy or energy services are given by $A_{E} E$. Here we ignore changes in the quality of the inputs, which will be addressed in the empirical section of the paper. As in Smulders and de Nooij (2003), labor and energy are given exogenously. Equation (2) is the equation of motion for capital that assumes, like Solow (1956), that the proportion of gross output that is saved is fixed at $s$ and that capital depreciates at a constant rate $\delta$. This assumes that the economy is closed to trade. We relax this assumption in the simulation section of the paper and the remaining assumptions could also be relaxed in a more complete model of growth.

Equation (1) explicitly ignores land and materials. In the pre-industrial economy energy was mostly produced by the agricultural and forestry sectors that used land as an input. The model represents that land input by the energy input, which later also includes fossil fuels. This is a tremendous simplification but allows us to show the effect of a minimal modification of the Solow growth model. By ignoring materials we implicitly assume that they are freely available in sufficient quantities. As we assume that labor and capital combine in a Cobb-Douglas function, as $\sigma \rightarrow 1$ and $\gamma_{E} \rightarrow 0$ the model tends towards the original Solow model, which represents the modern growth regime. In this case, $K$ and $Y$ will grow in the steady-state at the rate of labor-augmentation. Additionally, the shares of capital and labor in GDP will be constant, in accord with one of Kaldor's (1957) stylized facts despite their non-constant shares of gross output. Also if $\sigma<1$ and $\gamma_{E}>0$, as $A_{E} E \rightarrow$ the term $\gamma_{E}^{1 / \sigma}\left(A_{E} E\right)^{\phi} \rightarrow 0$, so that the model tends towards the Solow model but with a higher capital stock and output due to the coefficient $\gamma_{V}^{1 / \sigma}$, as discussed below. If $\sigma \rightarrow 1$ with non-zero $\gamma_{E}$, the production function is the Cobb-Douglas function with a resource input at the heart of the extensive literature on growth and non-renewable resources based on Dasgupta and Heal (1974), Solow (1974), and Stiglitz (1974).

The production function (1) has two limits to substitution (Stern, 1997). First, energy is essential to production and if $\sigma<1$ a minimum quantity of energy is required to produce any given level of output. This is a "static" limit to substitution. Second, energy is required to produce capital and as long as $\delta>0$, maintenance of the capital stock requires an ongoing energy input. Therefore, there is an additional limit to the degree to which capital can be substituted for energy. This can be thought of as a "dynamic" limit to substitution.

5. The fact that these parameters are fixed does not mean that the cost share of energy is fixed. As shown in equation (24), the cost share is also a function of other variables and parameters. This parameterization ensures that for $\gamma_{V} A_{L}^{\beta} L^{\beta} K^{1-\beta}=\gamma_{E} A_{E} E$ the level of output is invariant to the elasticity of substitution. $\gamma_{V}$ and $\gamma_{E}$ are only identifiable econometrically if a restriction is placed on the augmentation indices. 


\section{Steady-State and Comparative Statics}

All the following results assume that $1>\sigma>0$. We can find the steadystate of the system by substituting (1) into (2) and setting $\Delta K=0$, which gives the following equation in the steady-state capital stock, $\bar{K}$ :

$$
-(\delta / s)^{\phi} \bar{K}^{\phi}+\gamma_{V}^{1 / \sigma}\left(A_{L} L\right)^{\beta \phi} \bar{K}^{\phi(1-\beta)}+\gamma_{E}^{1 / \sigma}\left(A_{E} E\right)^{\phi}=0
$$

The existence and stability of this equilibrium are discussed in the Appendix. There is no general analytical solution to (3), so apart from special cases such as $\beta=2 / 3,0.5,1 / 3$ etc. we must use numerical methods to find the steady-state solution. Though there is no general solution for the steady-state capital stock, we can apply the implicit function theorem to (3) to determine how each factor affects the steady-state capital stock. As at the steady-state equilibrium $\delta>$ $s \partial Y / \partial \bar{K}$, the term $\delta-s \partial Y / \partial \bar{K}$ is positive and the derivatives and their signs are as follows:

$$
\begin{aligned}
& \frac{\partial \bar{K}}{\partial s}=\frac{Y}{\delta-s \partial Y / \partial \bar{K}}>0 \\
& \frac{\partial \bar{K}}{\partial \gamma_{E}}=\frac{s Y^{1-\phi}\left(\left(A_{E} E / \gamma_{E}\right)^{\phi}-\left(A_{L}^{\beta} L^{\beta} K^{1-\beta} /\left(1-\gamma_{E}\right)\right)^{\phi}\right)}{\sigma \phi(\delta-s \partial Y / \partial \bar{K})} \\
& \frac{\partial \bar{K}}{\partial \phi}=\frac{s Y}{\phi(\delta-s \partial Y / \partial \bar{K})} \\
& \left(\frac{\gamma_{V}\left(A_{L}^{\beta} L^{\beta} K^{1-\beta} / \gamma_{V}\right)^{\phi} \ln \left(A_{L}^{\beta} L^{\beta} K^{1-\beta} / \gamma_{V}\right)+\gamma_{E}\left(A_{E} E / \gamma_{E}\right)^{\phi} \ln \left(A_{E} E / \gamma_{E}\right)}{Y^{\phi}}-\ln Y\right) \\
& \frac{\partial \bar{K}}{\partial \beta}=\frac{s Y^{1-\phi}\left(A_{L}^{\beta} L^{\beta} \bar{K}^{1-\beta}\right)^{\phi} \gamma_{V}^{1 / \sigma}(\ln L-\ln \bar{K})}{\delta-s \partial Y / \partial \bar{K}} \\
& \frac{\partial \bar{K}}{\partial \delta}=\frac{-\bar{K}}{\delta-s \partial Y / \partial \bar{K}}<0 \\
& \frac{\partial \bar{K}}{\partial E}=\frac{s Y^{1-\phi} \gamma_{E}^{1 / \sigma} A_{E}^{\phi} E^{\phi-1}}{\delta-s \partial Y / \partial \bar{K}}>0 \\
& \frac{\partial \bar{K}}{\partial L}=\frac{s Y^{1-\phi} \beta \gamma_{V}^{1 / \sigma} A_{L}^{\beta \phi} L^{\beta \phi-1} \bar{K}^{(1-\beta) \phi}}{\delta-s \partial Y / \partial \bar{K}}>0 \\
& \frac{\partial \bar{K}}{\partial A_{L}}=\frac{s Y^{1-\phi} \beta \gamma_{V}^{1 / \sigma} A_{L}^{\beta \phi-1}\left(L^{\beta} \bar{K}^{(1-\beta)}\right)^{\phi}}{\delta-s \partial Y / \partial \bar{K}}>0 \\
& \frac{\partial \bar{K}}{\partial A_{E}}=\frac{s Y^{1-\phi} \gamma_{E}^{1 / \sigma} A_{E}^{\phi-1} E^{\phi}}{\delta-s \partial Y / \partial \bar{K}}>0
\end{aligned}
$$




\section{4 / The Energy Journal}

The results show that a higher savings rate always increases the size of the steadystate capital stock while higher depreciation rates result in smaller equilibrium stocks of capital. Equation (5) shows that the sign of the derivative with respect to the energy share parameter depends on the relative abundance of energy etc. When energy is abundant putting more weight on energy's contribution to production increases the steady-state capital stock. But when energy is scarce the reverse is true. This is not dependent on whether the elasticity of substitution is greater or smaller than unity. Klump and Preissler (2000) demonstrate that for $\beta=0$ (6) is positive. Equation (7) shows that the effect of the labor share of income depends on the capital/labor ratio. When labor is abundant relative to capital, increasing its share increases the optimal capital stock and vice versa. The effects of the two non-capital inputs-labor and energy — and their augmentation indices on the steady-state capital stock are always positive as one might expect.

\section{Steady-State Growth}

In our model, as in the Solow model, as there are constant returns to scale, increasing the labor force by the same amount as the other inputs has no effect on output per capita. However, also because of constant returns to scale, increasing the population without increasing the energy supply reduces output per capita as in the conventional Malthusian-Ricardian model. In the standard Solow model with a Cobb-Douglas production function, labor-augmenting technical change cannot be distinguished from factor neutral technical change. In the Solow model, steady-state growth in output per capita is possible as long as labor can be augmented by technological change. However, in the case of the CES function, (1), technical change that augments labor does not augment energy and vice versa. To explore this result we can plot the derivative of the steady-state capital stock with respect to the augmentation index of labor (11) against effective energy, $A_{E} E$ (Figure 2). We set $\beta=0.5, \gamma=0.1, s=0.1, \delta=0.05, L=1, E=1$, $A_{L}=1$, determine $K$ according to equation (A2), and allow the elasticity of substitution and $A_{E}$ to vary. For low elasticities of substitution and low levels of effective energy, labor-augmenting technical change has little effect on the optimal capital stock. For high levels of the energy augmentation index (or equivalently energy supply) labor-augmenting technical change has a positive effect of constant magnitude. Allowing for more substitutability results in more of an effect of labor augmentation at low levels of energy, as we would expect. For a CobbDouglas function without energy $\partial \bar{K} / \partial A_{L}$ is a constant with a value of 40 in this case. So the addition of the energy input reduces the effect of labor augmentation on growth at low levels of energy and increases it at high levels of effective energy.

Equation (A2) is homogenous of degree one in the augmentation indices. Therefore, if both rates of technological change are equal, the capital stock will grow at the same rate in the long-run and due to constant returns to scale, so will gross output. The Appendix proves that this is true more generally too. If energy 


\section{Figure 2: Energy Constraint on Growth}

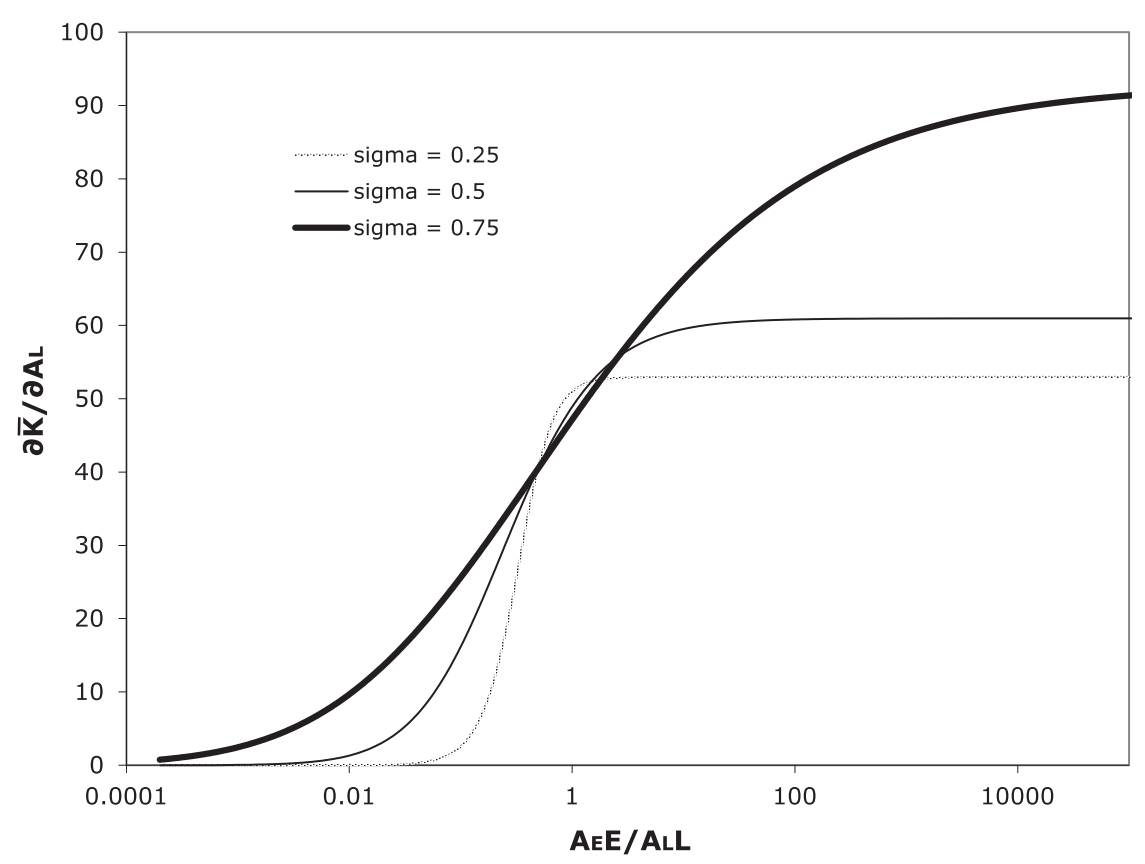

quantity is fixed and there is no energy augmenting technical change the economy eventually converges on a steady-state where $K$ and $Y$ are constant despite ongoing augmentation of labor. Even if there was no depreciation of capital, so that the capital stock kept growing, the low elasticity of substitution production function requires a minimum input of effective energy for any given output level and so growth would eventually halt anyway. The only way out of this constraint is for there to either be an increase in the quantity of energy, for there to be energyaugmenting technical progress, or for a switch to higher quality fuels to occur. The Industrial Revolution involved all of these.

\section{Input Prices, Income Shares, and Energy Intensity}

The marginal products of the three inputs are:

$$
\begin{aligned}
& \frac{\partial Y}{\partial K}=(1-\beta) \gamma_{V}^{1 / \sigma}\left(A_{L} L / K\right)^{\beta \phi}(Y / K)^{1-\phi} \\
& \frac{\partial Y}{\partial L}=\beta \gamma_{V}^{1 / \sigma}\left(A_{L}^{\beta} K^{(1-\beta)}\right)^{\phi} Y^{1-\phi} L^{\beta \phi-1} \\
& \frac{\partial Y}{\partial E}=\gamma_{E}^{1 / \sigma} A_{E}^{\phi}(Y / E)^{1-\phi}
\end{aligned}
$$


The output elasticities of the three inputs are, therefore, given by:

$$
\begin{aligned}
& \frac{\partial \ln Y}{\partial \ln K}=(1-\beta) \gamma_{V}^{1 / \sigma}\left(\left(A_{L} L\right)^{\beta} K^{(1-\beta)} / Y\right)^{\phi} \\
& \frac{\partial \ln Y}{\partial \ln L}=\beta \gamma_{V}^{1 / \sigma}\left(\left(A_{L} L\right)^{\beta} K^{(1-\beta)} / Y\right)^{\phi} \\
& \frac{\partial \ln Y}{\partial \ln E}=\gamma_{E}^{1 / \sigma}\left(A_{E} E / Y\right)^{\phi}
\end{aligned}
$$

and GDP is given by:

$$
G=Y\left[1-\frac{\partial \ln Y}{\partial \ln E}\right]=Y-\gamma_{E}^{1 / \sigma}\left(A_{E} E\right)^{\phi} Y^{1-\phi}
$$

As explained above, if effective energy, $A_{E} E$, is growing as fast as the rate of labor-augmenting technical progress in the steady-state, output will too and the energy output elasticity (18) will be constant over time. In order to find a declining energy cost share as seen in Sweden from 1800 to the late 20th century (Kander, 2002), the rate of expansion of effective energy (rate of energy-augmenting technical change plus the rate of increase in energy quality and quantity) has to have been greater than the rate of labor-augmenting technical progress (and increase in labor quality), assuming competitive markets. This would result in output growing slower than effective energy.

\section{DATA}

We use primary energy use data. For all modern energy carriers, such as coal, oil, and primary electricity, there are reliable historical statistical sources but for traditional fuels such as fuelwood, food, and fodder this is not the case, so estimates must be made. We use the estimates developed by Kander (2002) who also tabulates the quantity and price series for the modern energy carriers. Estimates of firewood use, which are a large share of total energy use in 19th century Sweden, are uncertain. The estimates are, however, similar in magnitude to those of Myllyntaus and Mattila (2002) for neighboring Finland, even though the estimation methods differ. Firewood prices are sensitive to assumptions of how much energy a particular amount of wood contained. We use the lower of the two firewood prices in Kander (2002).

We aggregated the various energy inputs using both simple addition of heat units and using Divisia indexation, which accounts for the effect of shifts in the mix of fuels used on the effective energy services provided. In order to avoid infinite percentage changes when new fuels are introduced, we ignore the change in the quantity of the new carriers in the first year each energy carrier was intro- 
duced. This method only affects a few years in our series, and the cost shares of these energy carriers were very small in the first few years after their introduction. The ratio of this index of energy volume to the sum of heat units is a measure of energy quality.

We use GDP and labor (number of employees) series from the national historical accounts for Sweden (Krantz and Schön, 2007). To obtain gross output, we followed Berndt et al. (1993), adding the value of energy to the value of GDP. The capital stock data has not yet been published, but was kindly provided to us by Lennart Schön. It is computed from the investment series that are part of the historical national accounts, using the usual perpetual inventory method with straight-line depreciation of buildings over 50 years and of machinery over 25 years. This means that, even though investment data is available from 1800 onwards, the stock of capital is only available from 1850. Therefore, although there are energy and GDP series are available from 1800 we can only estimate the full model from 1850 on.

\section{ECONOMETRIC MODEL AND RESULTS}

Because there are two technology trends we need at least two equations to identify the trends (Harvey and Marshall, 1991). Equations that are potentially useful include the production function (1) and energy output elasticity (18) replacing the elasticity on the left-hand side of (18) with the share of energy in gross output. Following Kim (1992) we use the log of the ratio of the cost share of energy to the cost share of capital-labor as we expect this variable to be more normally distributed. We also take logarithms of (1) due to the high level of heteroskedasticity in the untransformed gross output series. We also use a different parameterization of the scale constants in the production function to allow for the effect of measurement units. The model is given by:

$$
\begin{aligned}
& \ln \frac{S_{E t}}{1-S_{E t}}=\ln \gamma_{E}+\frac{\sigma-1}{\sigma} \\
& \quad\left[\ln A_{E t}-\beta \ln A_{L t}+\ln \left(Q_{t} E_{t}\right)-\beta \ln L_{t}-(1-\beta) \ln K_{t}\right]+\varepsilon_{E t} \\
& \ln Y_{t}=\ln \gamma_{0}+\frac{\sigma}{\sigma-1} \ln \left[\left(A_{L t}^{\beta} L_{t}^{\beta} K_{t}^{1-\beta}\right)^{\frac{\sigma-1}{\sigma}}+\gamma_{E}\left(A_{E t} Q_{t} E_{t}\right)^{\frac{\sigma-1}{\sigma}}\right]+\varepsilon_{Y t}
\end{aligned}
$$

where $Q$ is the quality index of energy, and $\varepsilon_{E t}$ and $\varepsilon_{Y t}$ are random error terms. Because we do not have good data on labor compensation, we do not estimate an equation for the cost share of labor and impose a fixed value on $\beta$ when estimating the remaining parameters. We obtain an estimate by reviewing the available sources. Edvinsson (2005) provides gross profit ratio data for 18502000. Multiplying this rate by the capital stock series and dividing by GDP shows that the capital share has fluctuated around a mean of $23 \%$ of GDP. Data for the Swedish manufacturing sector supplied by Lennart Schön show an average wage 


\section{8 / The Energy Journal}

share of $72 \%$ from 1875 and 2009. Both of these are fairly low values for the income share of capital. Most estimated values for other countries are in the range of 0.3 to 0.5 (Mankiw et al., 1992; Madsen, 2007). Still, there is no reason not to use the data we have, so we, therefore, treat $\beta$ as a known parameter with a value of 0.75 .

The states of technology in (20) and (21) are unobserved and are likely to be correlated with the explanatory variables (Stern, 2010b). If this is the case, parameter estimates will be biased. Instrumental variables using lagged values of the explanatory variables is unlikely to be an effective method as the lags will also be correlated with the state of technology. Therefore, in order to deal with the potential endogeneity issue, in addition to using the non-linear least squares (NLLS) estimator we also use the dynamic non-linear least squares (DNLLS) estimator that adds leads and lags of the first differences of the explanatory variables (Stock and Watson, 1993; Choi and Saikkonen, 2010). Two leads and lags of the first differences are used as well as the contemporaneous first difference of the logs of energy volume (energy quantity multiplied by energy quality) and the capital-labor aggregate. We use the Newey and West (1987) approach to computing the covariance matrix of the coefficients for all models using two correlated lags. We estimate models with constant rates of energy- and laboraugmentation as well as models with rates that are different in each half century. Assuming a constant rate of augmentation, $\ln A_{i t}=\tau_{i 1} t_{1850}$ where $t_{1850}$ is a time trend equal to zero in 1850 and $i$ refers to either labor or energy. For variable rates of augmentation we use the following formula: $\ln A_{i t}=\tau_{i 1} t_{1850}+\tau_{i 2} t_{1900}+$ $\tau_{i 3} t_{1950}$ where $t_{1900}$ is a time trend equal to zero for years up till and including 1900 and $t_{1950}$ is equal to zero up to and including 1950 and increasing by one per year from 1951 on.

Table 1 presents the results. All regressions use annual data from 1853 to 1998 because of the leads and lags required by the DNLLS estimator. Estimates of the coefficients of the lags and leads variables are omitted. It is safe to assume that all the key time-series in the model have stochastic trends and so we do not engage in formal testing of this hypothesis but we do apply three cointegration tests to the residuals. Choi and Saikkonen (2010) provide the first cointegration tests for the general non-linear model. The procedure tests the null hypothesis of cointegration by testing whether the residuals of the equations are stationary. The test uses the same basic test statistic as the KPSS test (Kwiatkowski et al., 1992) but applies a Bonferroni procedure to subsamples of the residuals. Hong and Wagner (2008) provide critical values. We also follow the recommendations of Hong and Wagner (2008) to compute the required long-run variance. We also use the Phillips and Ouliaris (1990) test of the null hypothesis of non-cointegration. Though, these tests do not formally apply to the non-linear case, equation (20) is linear in the variables.

The estimated parameters are fairly consistent across the technological change specifications and there is little difference between the NLLS and DNLLS estimates. Models with variable rates of technological change have, however, 
Table 1: Econometric Estimates

\begin{tabular}{|c|c|c|c|c|c|c|}
\hline \multicolumn{3}{|l|}{ Model } & $1 \mathrm{~S}$ & 1D & $3 \mathrm{~S}$ & $3 \mathrm{D}$ \\
\hline \multirow[t]{9}{*}{ Parameter Estimates } & \multicolumn{2}{|l|}{$\gamma_{0}$} & $\begin{array}{c}1.652 \\
(0.146)\end{array}$ & $\begin{array}{c}1.731 \\
(0.171)\end{array}$ & $\begin{array}{c}2.537 \\
(0.408)\end{array}$ & $\begin{array}{c}2.696 \\
(0.472)\end{array}$ \\
\hline & \multicolumn{2}{|l|}{$\gamma_{E}$} & $\begin{array}{c}0.147 \\
(0.017)\end{array}$ & $\begin{array}{c}0.161 \\
(0.019)\end{array}$ & $\begin{array}{c}0.211 \\
(0.042)\end{array}$ & $\begin{array}{c}0.228 \\
(0.040)\end{array}$ \\
\hline & \multicolumn{2}{|l|}{$\sigma$} & $\begin{array}{c}0.663 \\
(0.019)\end{array}$ & $\begin{array}{c}0.686 \\
(0.019)\end{array}$ & $\begin{array}{c}0.645 \\
(0.041)\end{array}$ & $\begin{array}{c}0.675 \\
(0.039)\end{array}$ \\
\hline & \multirow[t]{3}{*}{$\tau_{E i}$} & $1850-2000$ & $\begin{array}{c}0.018 \\
(0.002)\end{array}$ & $\begin{array}{c}0.019 \\
(0.002)\end{array}$ & $\begin{array}{c}0.028 \\
(0.004)\end{array}$ & $\begin{array}{c}0.030 \\
(0.004)\end{array}$ \\
\hline & & $1900-2000$ & & & $\begin{array}{r}-0.014 \\
(0.002)\end{array}$ & $\begin{array}{r}-0.016 \\
(0.002)\end{array}$ \\
\hline & & $1950-2000$ & & & $\begin{array}{r}-0.003 \\
(0.003)\end{array}$ & $\begin{array}{c}0.005 \\
(0.003)\end{array}$ \\
\hline & \multirow[t]{3}{*}{$\tau_{L i}$} & $1850-2000$ & $\begin{array}{c}0.011 \\
(0.001)\end{array}$ & $\begin{array}{c}0.012 \\
(0.001)\end{array}$ & $\begin{array}{r}-0.006 \\
(0.002)\end{array}$ & $\begin{array}{r}-0.006 \\
(0.003)\end{array}$ \\
\hline & & $1900-2000$ & & & $\begin{array}{c}0.019 \\
(0.002)\end{array}$ & $\begin{array}{c}0.018 \\
(0.003)\end{array}$ \\
\hline & & $1950-2000$ & & & $\begin{array}{c}0.008 \\
(0.002)\end{array}$ & $\begin{array}{c}0.009 \\
(0.002)\end{array}$ \\
\hline \multirow[t]{4}{*}{ Cointegration Tests } & \multirow[t]{2}{*}{$\mathrm{P}-\mathrm{O} \hat{Z}_{t}$} & Eq 20 & -2.70 & -2.70 & $-4.90^{1}$ & $-4.57^{1}$ \\
\hline & & Eq 21 & -1.82 & -2.07 & $-3.85^{5}$ & $-3.68^{10}$ \\
\hline & \multirow{2}{*}{ P-O $\hat{Z}_{\alpha}$} & Eq 20 & -11.85 & -11.62 & $-42.78^{1}$ & $-37.30^{1}$ \\
\hline & & Eq 21 & -5.24 & -5.72 & $-26.55^{10}$ & $-24.15^{10}$ \\
\hline & \multirow[t]{2}{*}{$\mathrm{C}-\mathrm{S}$} & Eq 20 & 1.61 & $1.67^{10}$ & 0.20 & 0.37 \\
\hline & & Eq 21 & 1.59 & 1.73 & 0.22 & 0.29 \\
\hline
\end{tabular}

Notes: Standard errors of parameter estimates in parentheses. P-O $\hat{Z}_{t}$ and $\hat{Z}_{\alpha}$ are the Phillips Ouliaris tests and C-S the Choi and Saikkonen test for cointegration in equations (20) and (21). The null of the $\mathrm{P}-\mathrm{O}$ test is non-cointegration and the null of the C-S test cointegration. Significant values are indicated by the relevant level in a superscript. Dates above technical change parameters are the periods of the trends associated with each one. To find the rate of technical change in model $3 \mathrm{~S}$ for 1900-1950, for example, add the parameters for 1850-1900 and 1900-1950. Model numbers refer to the number of technical change periods and whether the model is Static or Dynamic.

slightly lower elasticities of substitution and the DNLLS estimates are slightly higher. The Phillips and Ouliaris cointegration tests fail to reject the null of noncointegration for either equation for both estimates of the constant rate of technical change model. But they do reject the null for all equations of the variable rate of technological change model. Only one of the Choi and Saikkonen test statistics is significant at the $10 \%$ level rejecting the null of cointegration for the cost share ratio equation in the constant rate of technological change model. However, it is 
clearly apparent that all the test statistics are much larger for the constant rate of technological change model, indicating that the variable rate model fits the data better.

The rate of energy augmentation is significantly slower after 1900 than before but does not change significantly (model 3S) or increases slightly (3D) after 1950. Labor augmentation is negative before 1900, is significantly positive after 1900 and is found to accelerate further after 1950. A negative rate of augmentation for labor seems to not make any sense, unless working hours reduced in the 19th century, which they did not. However, we cannot distinguish between labor- and capital-augmenting technical change and Holmqvist (2003) and Schön (2004) found that TFP growth was negative in Swedish industry and manufacturing during this period of capital deepening in the late 19th century. Another possible explanation is that the elasticity of substitution between capital and labor is actually less than unity as suggested by recent research (Chirinko, 2008). We found that imposing a lower elasticity of substitution between capital-labor and energy resulted in non-negative labor augmentation in each period. This suggests that our estimates of the elasticity of substitution, which range from 0.64 to 0.69 might be somewhat conservatively high. However, because we lack good data on the cost shares of capital and labor we have not pursued this further.

\section{HISTORICAL AND COUNTERFACTUAL SIMULATIONS}

To understand the historical role of energy in growth, in this section we simulate the model using the available data for Sweden over the 19th and 20th centuries. The theoretical model presented above assumes that the economy is closed but Sweden is in fact a small open economy. Benge and Wells (2002) developed an open economy version of the Solow model that assumes that the capital stock adjusts instantaneously so that the marginal product of capital is equal to the rate of depreciation plus the exogenous world real interest rate. Therefore, in our counterfactual simulations we assume that the marginal product of capital is equal to the value from the base case simulation. In other words, the model consists of equation (1) and the capital stock, $K^{*}$, is chosen so that:

$$
m_{t}=\gamma_{0}^{\phi}(1-\beta)\left(A_{L t} L_{t} / K^{*}\right)^{\beta \phi}\left(Y\left(K^{*}\right) / K^{*}\right)^{1-\phi}
$$

holds true, where $m_{t}$ is the marginal product of capital in the base case simulation. Equation (22) is solved numerically. The simulations predict GDP and the capital stock given exogenous labor, energy supply, energy quality, technological change, and the rate of return on capital. We use the parameter values from model 3D in Table 1.

For the period 1800-1850, we do not have capital stock or labor data, so the simulation is more speculative than in subsequent years. We assume that prior to 1850 the labor force was the same $38.6 \%$ of the population that it was in 1850. We interpolated the 1800 population using data from Angus Maddison's 
website. Population grew by $0.6 \%$ p.a. between 1700 and 1820 . We estimate the population in 1800 as 2.3 million and, therefore, the labor force was 885,000 . We assume that the rate of labor-augmenting technical change is zero prior to 1850 , though a negative rate would have given a better fit to the data. We assumed that the initial capital stock was SEK 300 million in 1910-1912 prices in 1800 and we then set the rate of energy augmentation over 1800-1850 to $1 \%$ per annum. We filled in capital data for 1800-1850 using (2) with a constant rate of saving from GDP of $5.7 \%$ and a depreciation rate of $6 \%$. These choices closely reproduce the level of GDP in 1800 and the capital stock in 1850 and result in a fairly constant rate of return on capital over the first half of the 19th century (Figure $3 \mathrm{~A})$. However, the estimated cost share of energy in gross output in 1800 is then 0.41 against the observed value of 0.51 . A negative rate of labor augmentation (of around $1 \%$ per annum) together with a higher rate of energy augmentation would raise the cost share of energy closer to the observed value while predicting GDP in 1800 correctly. Alternatively, a lower elasticity of substitution could be imposed.

Figure 4 shows fitted GDP per capita using observed capital for 1850 2000 and observed GDP. Fitted GDP per capita rises from SEK(1910-1912) 157 in 1800 to 5,227 in 2000 . The fit is fairly good despite technical change being constant for 50 years at a time. However, observed GDP is much more volatile (Figure 5). There are three sources of volatility in our model—labor, capital stock, and energy quantity and quality. The volatility of the labor series is extremely variable. For long periods the series grows at a constant rate and at other times grows very erratically. The energy series has low volatility before about 1875 , as a result of the way in which it was constructed. In that period, traditional fuels still played a major role in the Swedish economy, and their use was estimated based on data on population, the number of cattle, and trends in the use of fuelwood, food, and fodder, without any attempt to produce annual fluctuations in response to climate or other short-run variations. Fitted and actual GDP match each other quite well in recent decades. As we go further back in time the fitted series is less and less volatile, but the volatility of observed GDP increases.

GDP per capita grows at $0.7 \%$ p.a. before 1850 and at up to $2.5 \%$ per annum after 1900 (Table 2). The step up in the growth rate around 1850 is quite noticeable in Figure 5. The quantity of energy supply grew very slowly up till 1850 and at an increasing rate after that. Energy quality only grew at a rapid rate after 1900, when electricity, coal, and oil increased their shares. The rate of energy augmentation peaked during 1850-1900 but was already at $1.3 \%$ per annum in 1800-1850. This makes historical sense as the energy efficiency of stoves, steam engines, and iron smelting all improved rapidly in the 19th Century (Kander, 2002). Like Fouquet and Pearson (2006) find for the UK, we find that energy services grew tremendously in Sweden over time. Total effective energy grew at $1.9 \%$ before 1850 and from $3.3 \%$ to $4.2 \%$ per annum after 1850 . Most importantly, though the rate of labor augmentation was non-positive before 1900, the economy was growing due to the increase in effective energy. Throughout the 
Figure 3: Sweden 1800-2000, Input Prices

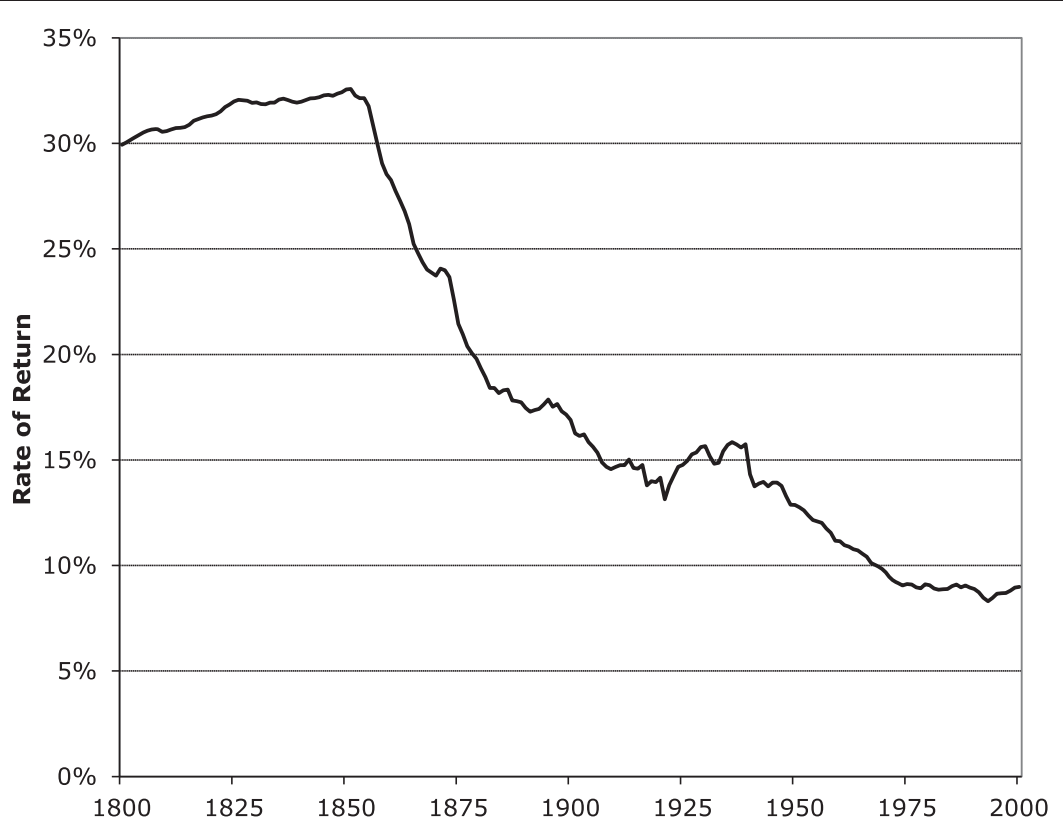

A. Rate of Return to Capital

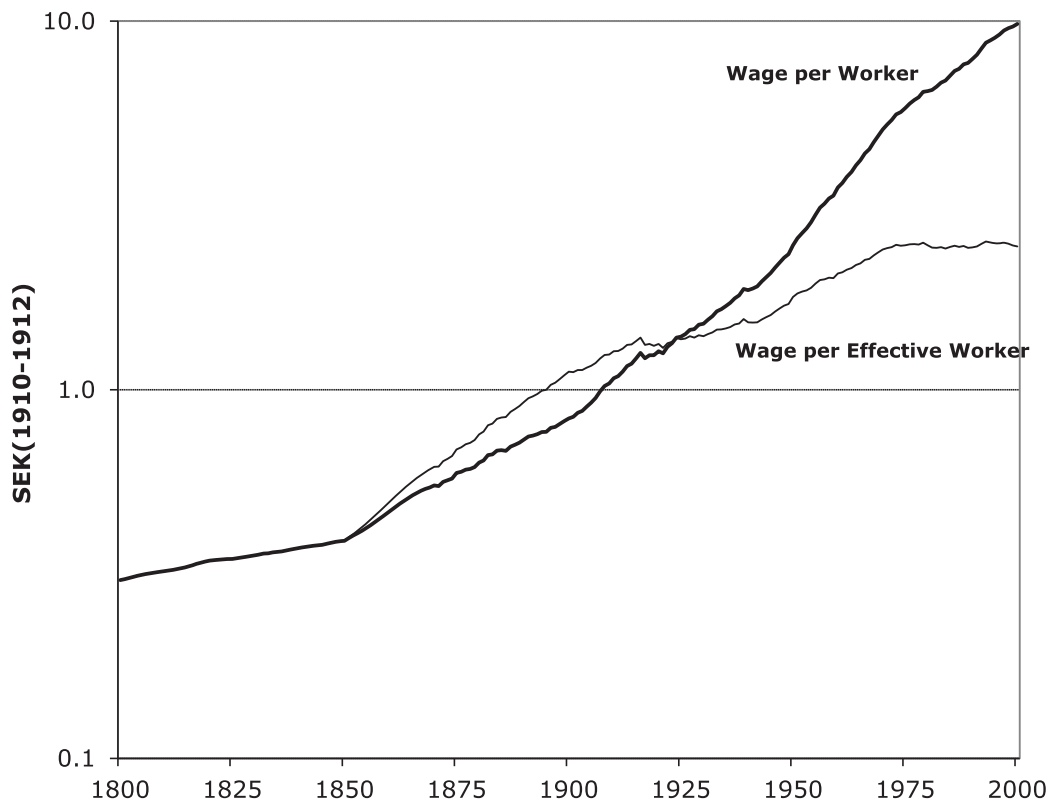

B. Wages, Thousands of SEK per Worker per Year

(continued)

Copyright (C) 2012 by the IAEE. All rights reserved. 
Figure 3: Sweden 1800-2000, Input Prices (continued)

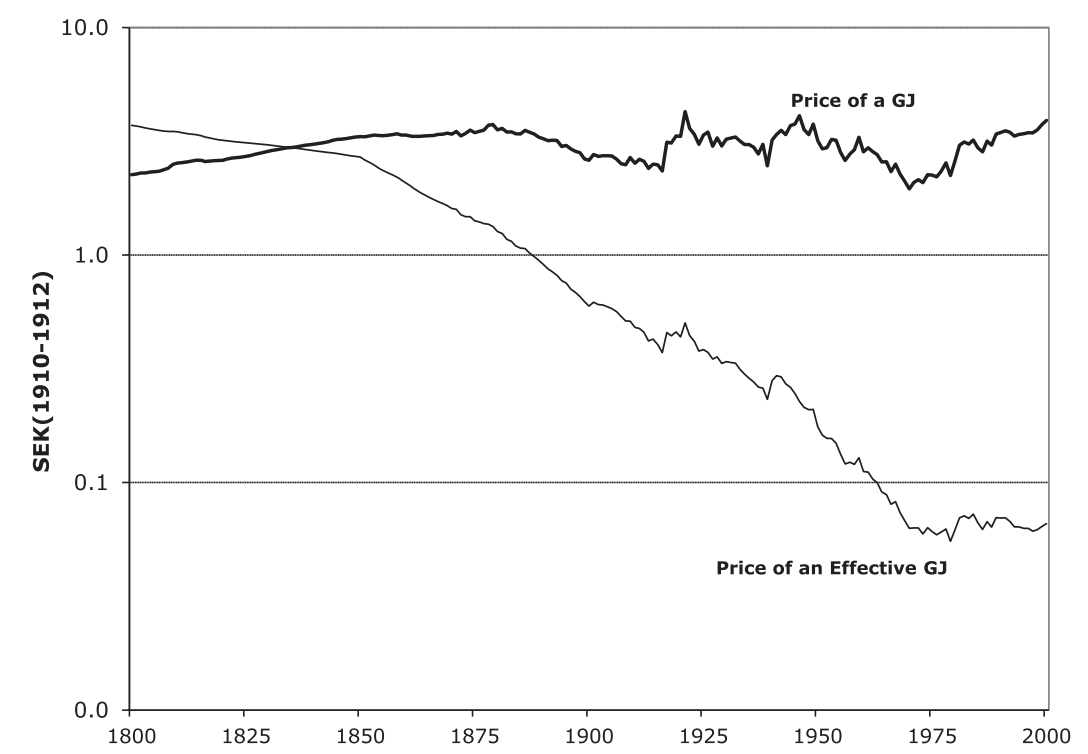

C. SEK per Gigajoule of Energy

Figure 4: Sweden 1800-2000, GDP per Capita

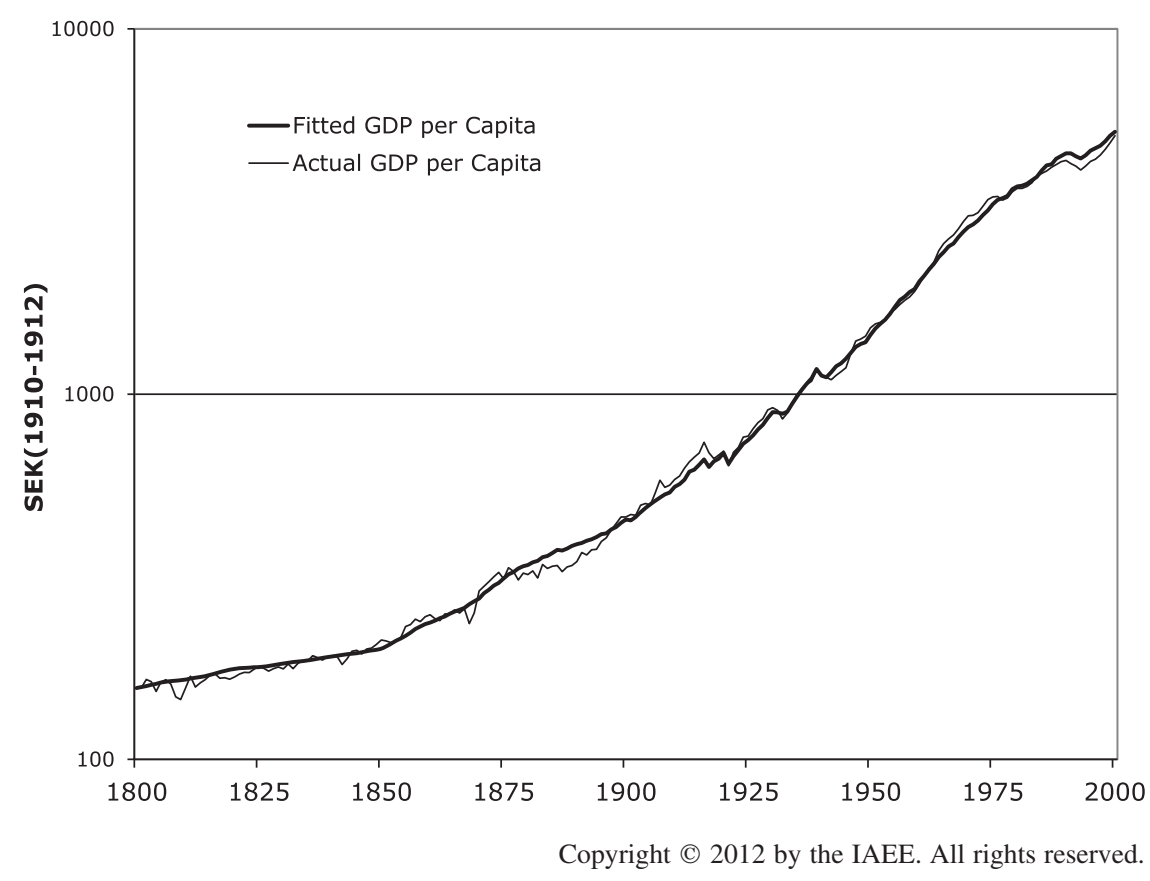


Table 2: Growth Rates

\begin{tabular}{|l|c|c|c|c|c|c|c|}
\hline Period & $\begin{array}{c}\text { Energy } \\
\text { Heat } \\
\text { Units }\end{array}$ & $\begin{array}{c}\text { Energy } \\
\text { Quality }\end{array}$ & $\begin{array}{c}\text { Energy } \\
\text { Augmentation }\end{array}$ & $\begin{array}{c}\text { Effective } \\
\text { Energy/Heat } \\
\text { Unit }\end{array}$ & $\begin{array}{c}\text { Total } \\
\text { Effective } \\
\text { Energy }\end{array}$ & $\begin{array}{c}\text { Labor } \\
\text { Augmentation }\end{array}$ & $\begin{array}{c}\text { GDP per } \\
\text { Capita }\end{array}$ \\
\hline $1800-1850$ & $0.2 \%$ & $0.4 \%$ & $1.0 \%$ & $1.4 \%$ & $1.7 \%$ & $0.0 \%$ & $0.7 \%$ \\
\hline $1850-1900$ & $1.5 \%$ & $-0.5 \%$ & $3.0 \%$ & $2.5 \%$ & $4.1 \%$ & $-0.6 \%$ & $1.6 \%$ \\
\hline $1900-1950$ & $1.6 \%$ & $1.5 \%$ & $1.4 \%$ & $2.9 \%$ & $4.5 \%$ & $1.2 \%$ & $2.4 \%$ \\
\hline $1950-2000$ & $1.9 \%$ & $0.5 \%$ & $1.9 \%$ & $2.4 \%$ & $4.3 \%$ & $2.2 \%$ & $2.5 \%$ \\
\hline Average & $1.3 \%$ & $0.5 \%$ & $1.8 \%$ & $2.3 \%$ & $3.7 \%$ & $0.7 \%$ & $1.8 \%$ \\
\hline
\end{tabular}

Figure 5: Sweden 1800-2000, GDP per Capita Growth

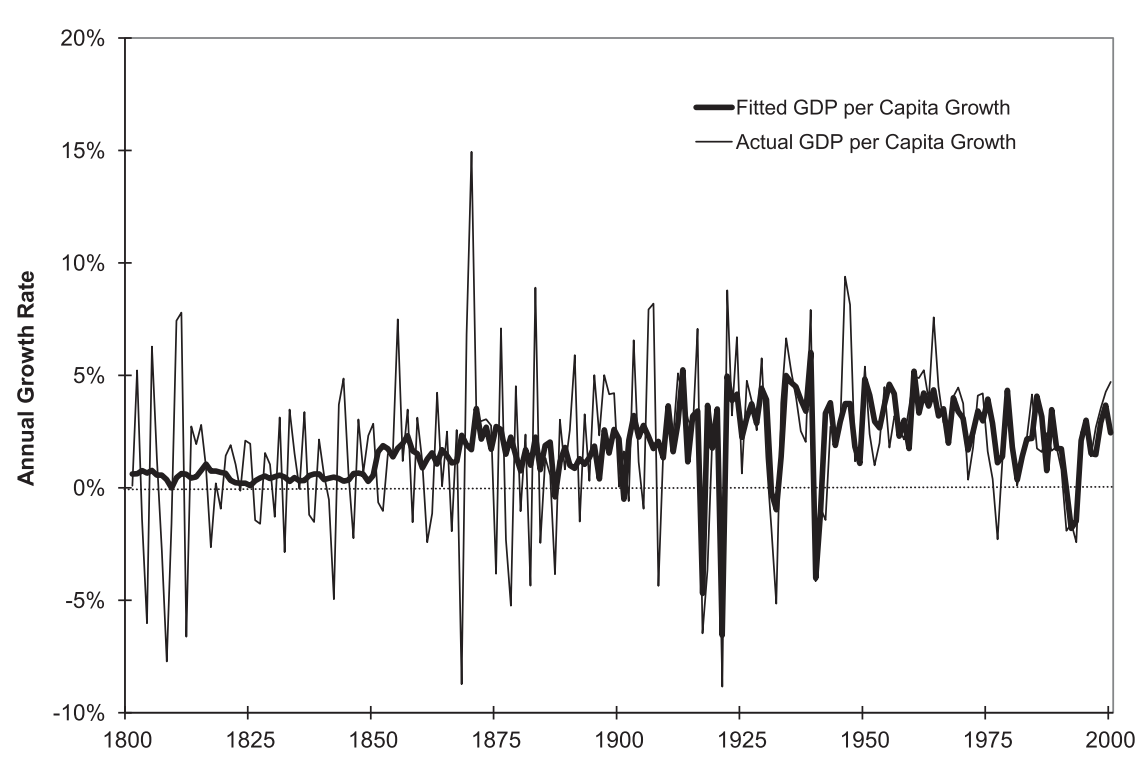

two hundred year period both the growth rate of effective energy and GDP per capita exceeded the rate of labor augmentation.

Figure 3 displays the time paths of the three input prices. The rate of return on capital rises from $30 \%$ in 1800 to a peak of $33 \%$ and then falls to $9 \%$ over time. Wage rates rise continuously. The price of an effective unit of labor has increased continuously over time but at a slowing rate. In Figure $5 \mathrm{c}$ the darker line is the price of a GJ of energy and the lighter line of an effective unit of energy. The price of a GJ is flat till the late 19th century before falling somewhat. The price of an effective unit of energy fell throughout the period.

Next, we simulate the economy under counterfactual scenarios to further understand the effects of changes in the quantity and quality of the inputs and Copyright (C) 2012 by the IAEE. All rights reserved. 
Table 3: Scenario Simulations

\begin{tabular}{|l|c|c|c|c|c|}
\hline \multicolumn{2}{|c|}{} & \multicolumn{2}{|c|}{ GDP per capita SEK(1910-1912) in: } \\
\hline Scenario & $\begin{array}{c}\text { Growth Rate of } \\
\text { GDP per capita }\end{array}$ & 1850 & 1900 & 1950 & 2000 \\
\hline Base Case & $1.8 \%$ & 201 & 454 & 1453 & 5227 \\
\hline Constant Energy & $1.3 \%$ & 187 & 307 & 789 & 2184 \\
\hline Constant Energy Quality & $1.7 \%$ & 176 & 458 & 1161 & 4123 \\
\hline Constant Energy Technology & $1.0 \%$ & 145 & 157 & 452 & 1232 \\
\hline Constant Effective Energy & $-0.5 \%$ & 116 & 87 & 76 & 62 \\
\hline Constant Labor Technology & $1.2 \%$ & 201 & 537 & 1145 & 1623 \\
\hline Constant Rate of Return & $1.6 \%$ & 202 & 404 & 1182 & 3780 \\
\hline
\end{tabular}

technological change on output (Table 3). Holding energy use constant at 1800 levels results in the economy growing by $0.5 \%$ less per annum over the two centuries. GDP per capita would not have been much lower in 1850 but by 2000 it would have only been $42 \%$ of its actual level. Energy quality has less effect. Because energy quality only improved in the 20th century, GDP per capita is the same in 1900 under this scenario as under the base case. By 2000, GDP per capita would have been $21 \%$ lower. Under the no energy augmentation scenario, GDP per capita would have been a lot lower in the late 19th century as well as the 20th century, ending at just $24 \%$ of actual levels in 2000. Energy-related innovation was, therefore, more important in the 19th century than increasing energy quantity or quality, while the latter became more important in the 20th century though energy innovation was still important. When we hold all three of these factors constant so that effective energy remains at the 1800 level, the economy collapses, with income per capita declining by $0.5 \%$ per annum and GDP per capita at one third of its 1800 level by 2000. GDP itself is lower too.

We also test the effects of labor augmentation and the rate of return on growth. If there had been no labor augmentation, the growth rate of the economy would have been $0.6 \%$ lower than in actuality. GDP per capita would, though, have been higher through 1900 due to the negative estimated rate of labor augmentation in the late 19th century. Labor augmentation becomes important in the late 20 th century so that GDP per capita would have been only $31 \%$ of its actual level in 2000 under this scenario. Most of the empirical growth literature uses data from this latter period and, therefore, mainstream growth theory emphasizes labor-augmenting technical change. Holding the rate of return constant at its level in 1800 has no effect on GDP per capita in 1850 but increasing effects after that.

In summary, each of the three components of effective energy had a major impact on economic growth in Sweden over the last couple of centuries. Without an increase in effective energy no economic growth could have occurred at all. On the other hand, labor augmentation had important effects in the second 
half of the 20th century as the economy became more freed from energy constraints and increased savings also had important effects.

\section{DISCUSSION}

The model presented in this paper should not be seen as a complete model of economic growth but rather as an exploration of a mechanism whereby energy can constrain or enable growth depending on its relative abundance. The simulations showed how innovations in the energy field were both a trigger of modern economic growth in Sweden and have been important in enabling growth ever since though labor-augmenting technological change has become more and more important over time.

In contrast to our results, as discussed in the introduction, Madsen et al. (2010) test for a short-run marginal effect of coal production on labor productivity while controlling for various innovation related variables and do not find a significant role for coal production in economic growth in the UK. A full investigation of the reason for the differences between their findings and ours would require estimating our model for the UK, which is something we plan to do in future research. Similarly, Crafts (2004) finds a fairly small contribution from steam to British economic growth but he only takes into account the contributions of steam through accumulation of capital in steam-intensive industries such as railways and the growth of TFP in the production of steam-using capital goods. He does not take into account productivity gains from using steam technologies in the economy. This "system boundary" reduces the estimated impact of steam on growth. Similarly, our framework attributes economic growth to the exogenous factors in our model-technological change and energy use. If we were to endogenize these variables then we would attribute the causes of growth to a different set of underlying variables.

The model we have presented is capable of incorporating a time-varying energy cost share, by allowing a low elasticity of substitution between energy and the other factors of production (labor and capital). Alternative explanations of the declining cost share need to be considered. One possibility that several people have suggested to us is change in the structure of production. In 1800 agriculture was the largest sector at 40\% of GDP followed by services and manufacturing industry (Krantz and Schön, 2007). This mix changed little over most of the rest of the 19th Century but industry increased its share from the late 19th century and more dramatically so in the 20th century. Kander (2002) finds that energy intensity declined largely due to changes within sectors rather due to structural change. Structural change in fact acted to increase energy intensity. Only after the 1970s did structural change result in a lowering of the aggregate energy intensity.

Another hypothesis is that the economy consists of two sectors with Cobb-Douglas technologies - a traditional sector with a very high energy cost share and a modern sector with a low energy cost share, along the lines of Hansen 
and Prescott (2002). This idea is harder to refute and direct empirical testing is not possible because national accounts are not organized on this basis. Relevant evidence in favor of the low elasticity of substitution hypothesis is that the elasticity is clearly less than unity in the short-run as witnessed in the oil price shocks of the 1970s. Additionally the energy cost share does seem to have declined further after animal power use effectively ended. The latter could be seen as an indicator of the traditional organic economy.

As mentioned in the introduction, energy could have acted as a constraint on growth before the Industrial Revolution even if the elasticity of substitution between energy and the other inputs is unity. However, in the face of laboraugmenting technical change, energy would only constrain growth in such a model if population grew in response to higher income in Malthusian fashion. Our model will be stuck in stagnation even if population does not respond to rising income, as is the case in the modern world, unless effective energy services can be increased.

What would change if we added a Malthusian population mechanism to our model? In the Malthus sector of the Hansen and Prescott model a technological improvement initially increases the potential steady-state income. The population response to that increased income results in diminishing returns because there are decreasing returns to capital and labor combined and, therefore, income per capita returns to the previous level. In practice it depends on how rapid technological change is and how quickly population responds to higher income per capita. In the Solow sector there are constant returns to labor and capital and hence the Malthusian effect does not occur. In our model, if population responds to higher income, the Malthusian effect should occur in response to factor neutral technical change to the same extent as in the Malthus sector of the Hansen and Prescott model as long as the energy supply does not increase alongside the increase in population. This is because there are decreasing to returns to capital and labor combined in our model.

The implications of our model for the future are very different to those of the Hansen-Prescott (2002) model. In their model, society has freed itself from the constraints of resource limitations. In our model, the economy is still latently constrained by resources. The future might be more energy constrained than the recent past due to both resource scarcity issues such as peak oil and environmental concerns such as climate change. Our model implies that energy availability might then become more of a constraint but that a higher level of energy-augmenting technology than there was in the past will mitigate this. Future growth depends on either maintaining increases in energy supply or augmenting energy through technological change in addition to labor-augmenting technological change. 


\section{APPENDIX}

\section{Uniqueness and Stability of Steady State}

For $\beta=0.5$, there are two roots to equation (3):

$$
a z^{2}+b z+c=0
$$

where $z=\bar{K}^{0.5 \phi}$. The solutions for the steady-state capital stock are:

$$
\begin{aligned}
\bar{K}=\left[\frac { 1 } { 2 ( \delta / s ) ^ { \phi } } \left(\gamma_{V}^{1 / \sigma}\left(A_{L} L\right)^{0.5 \phi}\right.\right. & \\
& \left.\left. \pm \sqrt{\gamma_{V}^{2 / \sigma}\left(A_{L} L\right)^{\phi}+4 \gamma_{E}^{1 / \sigma}\left((\delta / s) A_{E} E\right)^{\phi}}\right)\right]^{\frac{2}{\phi}}
\end{aligned}
$$

As $4 \gamma_{E}\left((\delta / s) A_{E} E\right)^{\phi}>0$, there is only one positive solution for $K$. As $A_{E} E$ increases, equation (A2) converges to:

$$
\lim _{A_{E} E \rightarrow} \bar{K}=\left(\frac{s \gamma_{V}^{1 /(\sigma-1)}}{\delta}\right)^{\frac{1}{\beta}} A_{L} L
$$

which is equal to the steady-state capital stock in the Solow model multiplied by $\gamma_{V}^{1 /(\beta(\sigma-1))}>1$. Therefore, the steady-state capital stock is higher than in the Solow model. However, when energy is scarce and substitutability is low the steadystate capital stock defined by (A2) or (3) can be less than the Solow steady-state capital stock. Is the negative root of (A2) relevant? In other words, can the system collapse to zero output or have more than one steady-state in the general case? In the Cobb-Douglas case $\phi=0$ and as $K$ approaches 0 the marginal product of capital (13) approaches infinity, guaranteeing that:

$$
s \frac{\partial Y}{\partial K}>\delta
$$

in the neighborhood of the origin and that, therefore, there is a single stable equilibrium. However, in general, CES functions other than the Cobb-Douglas function do not satisfy the Inada conditions (Barelli and de Abreu Pessoa, 2003). It is possible that for extreme parameter values-low savings rate, high depreciation rates, high levels of $\beta$ and low levels of $\sigma$-that (A4) is not met neither near the origin nor for any positive value of $K$ so that there is no positive equilibrium level of capital. Klump and Preissler (2000) derive a similar result for the capital-labor low constant elasticity of substitution production function. The derivative of (13) with respect to $K$ is:

$$
\begin{aligned}
& \frac{\partial^{2} Y}{\partial K^{2}}=(1-\beta) \gamma_{V}^{1 / \sigma}\left(A_{L} L\right)^{\beta \phi} Y^{-\phi} K^{\phi-\beta \phi-1}\left((1-\phi) \frac{\partial Y}{\partial K}\right. \\
&\left.+(\phi-\beta \phi-1) \frac{Y}{K}\right)
\end{aligned}
$$


For $\sigma>1$ this is obviously negative. For $\sigma<1$, the first term in the brackets is positive and the second negative and so it is not clear that the derivative is always negative. From (13) and (1) the expression in the brackets is:

$$
\begin{aligned}
& \left((1-\phi) \frac{\partial Y}{\partial K}+(\phi-\beta \phi-1) \frac{Y}{K}\right) \\
& \quad=\left(\frac{(1-\phi)(1-\beta) \gamma_{V}^{1 / \sigma}\left(\left(A_{L} L\right)^{\beta} K^{1-\beta}\right)^{\phi}}{\gamma_{V}^{1 / \sigma}\left(A_{L}^{\beta} L^{\beta} K^{1-\beta}\right)^{\phi}+\gamma_{E}^{1 / \sigma}\left(A_{E} E\right)^{\phi}}-(1-\phi)(1-\beta)-\beta\right) \frac{Y}{K}
\end{aligned}
$$

Multiplying the term in the brackets on the RHS here by $\gamma_{V}^{1 / \sigma}\left(A_{L}^{\beta} L^{\beta} K^{1-\beta}\right)^{\phi}+$ $\gamma_{E}^{1 / \sigma}\left(A_{E} E\right)^{\phi}$ gives:

$$
-\beta \gamma_{V}^{1 / \sigma}\left(A_{L}^{\beta} L^{\beta} K^{1-\beta}\right)^{\phi}-((1-\phi)(1-\beta)+\beta) \gamma_{E}^{1 / \sigma}\left(A_{E} E\right)^{\phi}<0
$$

Therefore, (A5) is negative too and if a steady state exists it is unique and stable.

\section{Steady State Growth}

Assuming that $L$ and $E$ are held constant for simplicity, the percentage rate of change in the steady-state capital stock is given by:

$$
\hat{\bar{K}}=\frac{\partial \ln \bar{K}}{\partial \ln A_{L}} \hat{A}_{L}+\frac{\partial \ln \bar{K}}{\partial \ln A_{E}} \hat{A}_{E}
$$

where "hats" indicate percentage or proportional rates of change. If the two rates of technological change are equal, substituting (11) and (12) into (A8) and then substituting in (13) gives:

$$
\hat{\bar{K}}=\left(\frac{s Y^{1-\phi}\left(\beta \gamma_{V}^{1 / \sigma}\left(A_{L}^{\beta} L^{\beta} \bar{K}^{(1-\beta)}\right)^{\phi}+\gamma_{E}^{1 / \sigma} A_{E}^{\phi} E^{\phi}\right)}{\delta \bar{K}-s(1-\beta) \gamma_{V}^{1 / \sigma}\left(A_{L}^{\beta} L^{\beta} \bar{K}^{(1-\beta)}\right)^{\phi} Y^{1-\phi}}\right) \hat{A}
$$

noting that at the steady-state equilibrium $\delta K=s Y$ we have:

$$
\hat{\bar{K}}=\left(\frac{Y^{1-\phi}\left(\beta \gamma_{V}^{1 / \sigma}\left(A_{L}^{\beta} L^{\beta} \bar{K}^{(1-\beta)}\right)^{\phi}+\gamma_{E}^{1 / \sigma} A_{E}^{\phi} E^{\phi}\right)}{Y-(1-\beta) \gamma_{V}^{1 / \sigma}\left(A_{L}^{\beta} L^{\beta} \bar{K}^{(1-\beta)}\right)^{\phi} Y^{1-\phi}}\right) \hat{A}
$$

Substituting in the expressions in equations (16) to (18) and simplifying yields:

$$
\hat{\bar{K}}=\left(\frac{\partial \ln Y / \partial \ln L+\partial \ln Y / \partial \ln E}{1-\partial \ln Y / \partial \ln \bar{K}}\right) \hat{A}
$$

which due to constant returns to scale is equal to the rate of technological change. Also due to constant returns to scale of the production function (1), gross output also increases at the same rate. 


\section{REFERENCES}

Aghion, P. and P. Howitt (1998). Endogenous Growth Theory. Cambridge, MA: MIT Press. Aghion, P. and P. Howitt (2009). The Economics of Growth. Cambridge, MA: MIT Press.

Allen, R. C. (2009). The British Industrial Revolution in Global Perspective. Cambridge: Cambridge University Press.

Ayres, R. U. and B. Warr (2005). "Accounting for growth: the role of physical work." Structural Change and Economic Dynamics 16: 181-209. http://dx.doi.org/10.1016/j.strueco.2003.10.003.

Ayres, R. U. and B. Warr (2009). The Economic Growth Engine: How Energy and Work Drive Material Prosperity. Cheltenham: Edward Elgar.

Barelli P. and S de Abreu Pessoa (2003). "Inada conditions imply that the production function must be asymptotically Cobb-Douglas." Economics Letters 81: 361-363. http://dx.doi.org/10.1016/ S0165-1765(03)00218-0.

Benge M. and G. Wells (2002). "Growth and current account in a small open economy." The Journal of Economic Education 33(2): 152-165. http://dx.doi.org/10.1080/00220480209596464.

Berndt, E. R., C. Kolstad, and J-K. Lee (1993). "Measuring the energy efficiency and productivity impacts of embodied technical change." Energy Journal 14: 33-55. http://dx.doi.org/10.5547/ ISSN0195-6574-EJ-Vol14-No1-2.

Brock W. A. and M. S. Taylor (2010). "The green Solow model." Journal of Economic Growth 15: 127-153. http://dx.doi.org/10.1007/s10887-010-9051-0.

Chirinko, R. S. (2008). “ $\sigma$ : The long and short of it.” Journal of Macroeconomics 30: 671-686. http:/ /dx.doi.org/10.1016/j.jmacro.2007.10.010.

Choi, I. and P. Saikkonen (2010). "Tests for nonlinear cointegration.” Econometric Theory 26: 682709. http://dx.doi.org/10.1017/S0266466609990065.

Cipolla, C. M. (1962). The Economic History of World Population. London: Pelican Books.

Clark, G. (2007). A Farewell to Alms: A Brief Economic History of the World. Princeton: Princeton University Press.

Cleveland C. J., R. Costanza, C. A. S. Hall and R. K. Kaufmann (1984). "Energy and the U.S. economy: A biophysical perspective." Science 225: 890-897. http://dx.doi.org/10.1126/science.225.4665.890.

Crafts, N. (2004). "Steam as a general purpose technology: a growth accounting perspective." Economic Journal 114: 338-351. http://dx.doi.org/10.1111/j.1468-0297.2003.00200.x.

Dasgupta, P. and G. Heal (1974). "The optimal depletion of exhaustible resources." The Review of Economic Studies 41(Symposium on the Economics of Exhaustible Resources): 3-28.

Di Maria, C. and S. Valente (2008). "Hicks meets Hotelling: the direction of technical change in capital-resource economies." Environment and Development Economics 13: 691-717. http:// dx.doi.org/10.1017/S1355770X08004567.

Edvinsson, R. (2005). Growth, Accumulation, Crisis: With New Macroeconomic Data for Sweden 1800-2000. Stockholm: Almqvist \& Wiksell International.

Fouquet, R. and P. J. G. Pearson (2006). "Seven centuries of energy services: the price and use of lighting in the United Kingdom (1300-2000).” The Energy Journal 27(1): 139-77. http://dx.doi.org/ 10.5547/ISSN0195-6574-EJ-Vol27-No1-8.

Fröling, M. (2011). "Energy use, population and growth, 1800-1970." Journal of Population Economics 24(3): 1133-1163. http://dx.doi.org/10.1007/s00148-009-0278-z.

Galor, O. (2005). "From stagnation to growth: unified growth theory." In P. Aghion and S. N. Durlauf, eds., Handbook of Economic Growth. Amsterdam: North Holland, Volume 1A pp. 171-294.

Galor, O. and D. N. Weil (2000). "Population, technology and growth: From Malthusian regime to the demographic transition." American Economic Review 90(4): 806-828. http://dx.doi.org/ 10.1257/aer.90.4.806.

Hall, C. P. Tharakan, J. Hallock, C. Cleveland, and M. Jefferson (2003). "Hydrocarbons and the evolution of human culture." Nature 426: 318-322. http://dx.doi.org/10.1038/nature02130.

Hansen, G. D. and E. C. Prescott (2002). "Malthus to Solow." American Economic Review 92(4): 1205-1217. http://dx.doi.org/10.1257/00028280260344731.

Copyright (C) 2012 by the IAEE. All rights reserved. 
Harvey, A. C., P. Marshall (1991). "Inter-fuel substitution, technical change and the demand for energy in the UK economy." Applied Economics 23: 1077-1086. http://dx.doi.org/10.1080/ 00036849100000011.

Holmquist, S. (2003). "Kapitalbildning i svensk industri 1870-1930." Lund Studies in Economic History 29.

Hong, S. H. and M. Wagner (2008). "Nonlinear cointegration analysis and the environmental Kuznets curve." Economics Series, Institute for Advanced Studies, Vienna 224.

Jones, C. I. (2001). "Was an industrial revolution inevitable? Economic growth over the very long run." Advances in Macroeconomics 1(2): 1-43. http://dx.doi.org/10.2202/1534-6013.1028.

Jones, C. I. (2002). Introduction to Economic Growth, 2nd edition. New York: W. W. Norton.

Jones, L. E. and R. E. Manuelli (2005). "Neoclassical models of endogenous growth: the effects of fiscal policy, innovation and fluctuations." In P. Aghion and S. N. Durlauf, eds., Handbook of Economic Growth. Amsterdam: North Holland Volume 1A pp. 13-66.

Kaldor, N. (1957). “A model of economic growth.” Economic Journal 67(268): 591-624. http:// dx.doi.org/10.2307/2227704.

Kander, A. (2002). "Economic growth, energy consumption and $\mathrm{CO}_{2}$ emissions in Sweden 1800 2000." Lund Studies in Economic History 19.

Kander, A., P. Malanima, and P. Warde (forthcoming). Power to the People-Energy and Economic Transformation of Europe over Four Centuries. Princeton: Princeton University Press.

Kim, H. Y. (1992). "The translog production function and variable returns to scale." Review of Economics and Statistics 74: 546-552. http://dx.doi.org/10.2307/2109500.

Klump, R. and H. Preissler (2000) CES production functions and economic growth." Scandinavian Journal of Economics 102(1): 41-56. http://dx.doi.org/10.1111/1467-9442.00183.

Koetse, M. J., H. L. F. de Groot, and R. J. G. M. Florax (2008). "Capital-energy substitution and shifts in factor demand: A meta-analysis." Energy Economics 30: 2236-2251. http://dx.doi.org/ 10.1016/j.eneco.2007.06.006.

Krantz, O. and L. Schön (2007). "Swedish historical national accounts 1800-2000.” Lund Studies in Economic History 41.

Kwiatkowski, D., P. C. B. Phillips, P. Schmidt, and Y. Shin (1992). "Testing the null hypothesis of stationarity against the alternative of a unit root: How sure are we that economic time series have a unit root?" Journal of Econometrics 54: 159-178. http://dx.doi.org/10.1016/03044076(92)90104-Y.

Landes, D. S. (1969). The Unbound Prometheus: Technological Change and Development in Western Europe from 1750 to the Present, Cambridge University Press, Cambridge.

Lucas, R. E. (2002). "The industrial revolution: past and future.” In R. E. Lucas, Lectures on Economic Growth. Cambridge MA: Harvard University Press pp. 109-188.

Madsen, J. B. (2007). "Technological spillover through trade and TFP convergence: 135 years of evidence for the OECD countries." Journal of International Economics 72: 464-480. http:// dx.doi.org/10.1016/j.jinteco.2006.12.001.

Madsen, J. B., J. B. Ang, and R. Banerjee (2010) Four centuries of British economic growth: the roles of technology and population." Journal of Economic Growth 15(4): 263-290. http:// dx.doi.org/10.1007/s10887-010-9057-7.

Mankiw, N.G., Romer, D. and D. N. Weil (1992). "A contribution to the empirics of economic growth." Quarterly Journal of Economics 107: 407-437. http://dx.doi.org/10.2307/2118477.

Myllyntaus, T. and T. Mattila (2002). "Decline or increase? The standing timber stock in Finland, 1800-1997." Ecological Economics 41: 271-288. http://dx.doi.org/10.1016/S0921-8009(02) 00034-4.

Newey, W. K and K. D. West (1987). "A simple, positive semi-definite, heteroskedasticity and autocorrelation consistent covariance matrix." Econometrica 55(3): 703-708. http://dx.doi.org/ $10.2307 / 1913610$.

Phillips, P. C. B. and S. Ouliaris (1990). "Asymptotic properties of residual based tests for cointegration.” Econometrica 58(1): 165-193. http://dx.doi.org/10.2307/2938339.

Pomeranz, K. (2001). The Great Divergence: China, Europe, and the Making of the Modern World Economy. Princeton: Princeton University Press.

Copyright (C) 2012 by the IAEE. All rights reserved. 


\section{2 / The Energy Journal}

Schön, L. (2004). "Total factor productivity in Swedish manufacturing in the period 1870-2000." In S. Heikkinen and J. L. van Zanden (eds.), Exploring Economic Growth: Essays In Measurement and Analysis. Amsterdam: Aksant.

Shin, Y. (1994). "A residual-based test of the null of cointegration against the alternative of no cointegration." Econometric Theory 10: 91-115. http://dx.doi.org/10.1017/S0266466600008240.

Smil, V. (1994). Energy In World History. Boulder, CO: Westview Press.

Smulders, S. and M. de Nooij (2003). "The impact of energy conservation on technology and economic growth." Resource and Energy Economics 25: 59-79. http://dx.doi.org/10.1016/S09287655(02)00017-9.

Solow, R. M. (1956). "A contribution to the theory of economic growth." Quarterly Journal of Economics 70: 65-94. http://dx.doi.org/10.2307/1884513.

Solow, R. M. (1974). "Intergenerational equity and exhaustible resources." Review of Economic Studies 41(Symposium on the Economics of Exhaustible Resources): 29-46.

Stern, D. I. (1993). "Energy use and economic growth in the USA: a multivariate approach." Energy Economics 15: 137-150. http://dx.doi.org/10.1016/0140-9883(93)90033-N.

Stern, D. I. (1997). "Limits to substitution and irreversibility in production and consumption: a neoclassical interpretation of ecological economics." Ecological Economics 21: 197-215. http:// dx.doi.org/10.1016/S0921-8009(96)00103-6.

Stern, D. I. (2000). "A multivariate cointegration analysis of the role of energy in the U.S. macroeconomy.” Energy Economics 22: 267-283. http://dx.doi.org/10.1016/S0140-9883(99)00028-6.

Stern, D. I. (2002). "Explaining changes in global sulfur emissions: an econometric decomposition approach." Ecological Economics 42: 201-220. http://dx.doi.org/10.1016/S0921-8009(02)000502.

Stern, D. I. (2010a). "Energy quality.” Ecological Economics 69(7): 1471-1478. http://dx.doi.org/ 10.1016/j.ecolecon.2010.02.005.

Stern D. I. (2010b). "Modeling international trends in energy efficiency and carbon emissions." Environmental Economics Research Hub Research Report 54.

Stiglitz, J. E. (1974). "Growth with exhaustible natural resources: the competitive economy." Review of Economic Studies 41(Symposium on the Economics of Exhaustible Resources): 139-152.

Stock, J. H. and M. Watson (1993). "A simple estimator of cointegrating vectors in higher order integrating systems.” Econometrica 61: 783-820. http://dx.doi.org/10.2307/2951763.

Tahvonen, O. and S. Salo (2001). "Economic growth and transitions between renewable and nonrenewable energy resources." European Economic Review 45(8): 1379-1398. http://dx.doi.org/ 10.1016/S0014-2921(00)00062-3.

Wilkinson, R. G. (1973). Poverty and Progress: An Ecological Model of Economic Development. London: Methuen.

Wrigley, E. A. (1988). Continuity, Chance, and Change: The Character of the Industrial Revolution in England. Cambridge: Cambridge University Press.

Wrigley, E. A. (2010). Energy and the English Industrial Revolution, Cambridge: Cambridge University Press. 